\title{
The concentration of carbon dioxide in conference rooms: a simplified model and experimental verification
}

\author{
T. Teleszewski ${ }^{1} \cdot$ K. Gładyszewska-Fiedoruk $^{1}$ (D)
}

Received: 21 January 2019 / Revised: 28 April 2019 / Accepted: 11 May 2019 / Published online: 27 May 2019

(c) The Author(s) 2019

\begin{abstract}
Based on an experimental study, a simplified model is constructed for the concentration of carbon dioxide in conference rooms with stack ventilation. The experiments were carried out in a conference room in the building of the Faculty of Civil and Environmental Engineering at Białystok University of Technology in Poland. Tests were performed with and without prior airing of the room by opening windows before sessions. The air supply was regulated by unsealing or opening of the windows. In all cases, a linear increase in the level of carbon dioxide was recorded during sessions. The increase in carbon dioxide concentration in rooms of this type is dependent primarily on the volume of the room, the number of people occupying it and the air change rate. In this work, a simplified comprehensive formula was developed to predict the concentration of carbon dioxide in rooms. The model may be applied for the design of systems of automatic regulation in ventilation installations and for analysis of carbon dioxide concentrations in closed rooms used by people. It is proposed that the model can be applied in the regulation of mechanical ventilation in rooms based on the concentration of carbon dioxide.
\end{abstract}

Keywords Carbon dioxide $\cdot$ Indoor air quality $\cdot$ Indoor microclimate $\cdot$ Simulation $\cdot$ Stack ventilation

\section{List of symbols}

a The coefficient

$a_{\mathrm{CO}_{2}} \quad$ Concentration computed

$a_{\mathrm{CO}_{2}, \text { ex }} \quad$ External concentration of $\mathrm{CO}_{2}$

$a_{\mathrm{CO}_{2}, \text { exp }} \quad$ Measured concentration of carbon dioxide in the room

$a_{\mathrm{CO}_{2}, t=0} \quad$ The initial $\mathrm{CO}_{2}$ concentration

$\mathrm{ACH} \quad$ Air change rate

$B \quad$ Constant value

$b \quad$ The coefficient

c The coefficient

CFD Computational fluid dynamics

d The coefficient

$e \quad$ The coefficient

$G \quad$ The quantity of carbon dioxide generated by all persons in the room

Editorial responsibility: M. Abbaspour.

K. Gładyszewska-Fiedoruk

k.gladyszewska@pb.edu.pl

1 Department of HVAC Engineering, Faculty of Civil Engineering and Environmental Engineering, Bialystok University of Technology, Wiejska 45E, 15-351 Białystok, Poland $g \quad$ Quantity of carbon dioxide exhaled by a

person depending on action being performed Heating, ventilation and air-conditioning systems

IAQ Indoor air quality

IEQ Indoor environmental quality

$k \quad$ Dimensionless factor depending on the air change rate

$m \quad$ Air change rate

$n \quad$ The number of persons

PACT-IAQ Preliminary assessment and control of indoor air quality

PM2.5 Particulate matter-diameter smaller than $2.5 \mu \mathrm{m}$

PM10 Particulate matter-diameter smaller than $10 \mu \mathrm{m}$

$Q \quad$ Rate of flow of air through the room

$t \quad$ Time

TVOC Total volatile organic compounds

$V \quad$ The room volume

$\Delta a_{\mathrm{CO}_{2}} \quad$ Measured increase in carbon dioxide concentration 


\section{Introduction}

Contamination of the air within rooms may originate both from the ambient external air penetrating into the interior and directly from internal sources.

Contaminants regarded as harmful to health have been identified and selected in the form of a list of contaminants to be taken into account in determining the IAQ index, defined by Salis et al. (2017). The selected substances are acetaldehyde, acrolein, $\alpha$-pinene, benzene, carbon dioxide, formaldehyde, naphthalene, nitrogen dioxide, PM10, PM2.5, radon, styrene, toluene, trichloroethylene, TVOC and mould (Salis et al. 2017). Some scientists view the IAQ index as an indicator of the concentration of $\mathrm{CO}_{2}$ (Khazaei et al. 2019; Zender-Świercz 2017, 2018).

Carbon dioxide is the most powerful predictor in the case of rooms occupied by large numbers of persons (Szczurek et al. 2015). Conference rooms belong to this category.

The permissible concentration of carbon dioxide in closed rooms is $1000 \mathrm{ppm}$. This is a minimum hygienic requirement recommended by standards (ASHRAE 2006; EN 13779: 2008; WHO 1990).

Small conference rooms often have only stack ventilation, which produces a small, constant flow of air in the room. The level of carbon dioxide in conference rooms has a significant effect on the comfort of the working conditions (Tham 2016).

In rooms occupied by numbers of people, the quality of the air is extremely important. In such rooms, tests are carried out for various biological (Weryszko-Chmielewska et al. 2018) and chemical (Rogula-Kozłowska et al. 2018) contaminants.

The rational use of natural ventilation favours improvement in air quality inside rooms (Silva et al. 2017; Yu et al. 2017; Mijakowski and Sowa 2017). In one study (Yao and Zhao 2017), field measurements were taken with the aim of understanding the static distribution of the natural ventilation coefficient. The method was based on a nonlinear fit of the carbon dioxide concentration. An analysis was made of factors such as type of window, degree of opening of window and area, in order to determine how they affect the rate of natural ventilation. It was found that the natural ventilation coefficient has a logistic distribution, with $\mu=0.86$ and $\sigma=0.88$.

A study by Deng et al. (2018) aimed to determine, by experimental and simulation methods, how the air change rate affects the removal of carbon dioxide. A series of experiments was carried out with different $\mathrm{ACH}$ values using sources of constant carbon dioxide contamination, in order to check the correctness of the simulations. The findings are important for practical applications in the design and control of ventilation systems from the health perspective.
Real-time monitoring of the thermal conditions in rooms requires dynamic models of temperature and air humidity. A computational fluid dynamics (CFD) model is too expensive in computational terms (Kong et al. 2015).

Wang et al. (2016) introduced a tool for preliminary assessment and control of room air quality (evaluation index), having the aim of obtaining concentrations of contaminants and simulating and estimating the contaminant loads. The simulation model was applied to industrial buildings, and measurements were taken for verification. Evaluation index is a promising tool for use in the monitoring of contaminants in indoor air.

Baranowski and Ferdyn-Grygierek (2015) and Arendt et al. (2017) attempted to model natural ventilation in a small single-family building, school building and multifamily building. They aimed to determine the value of the potential of natural ventilation, which can provide significant information for architects, enabling the correct design of natural ventilation strategies at the concept stage and when designing buildings.

Kusiak et al. (2010) presented a data-based approach to the modelling of sensors of internal air quality (IAQ). The paper includes the results of computations based on models constructed using various algorithms. Models built from data mining algorithms may serve as virtual IAQ sensors in buildings and may be used for online monitoring.

Szczurek et al. (2015) described an original method for analysing the effect of various factors on variation in room air parameters. It distinguishes three types of effects on such variation: promotion, delay and stabilisation. It was determined that all of these types of effect apply to variation in $\mathrm{CO}_{2}$ levels. The method may prove useful in evaluating the susceptibility of a building environment to a wide range of internal factors, including carbon dioxide concentration.

A model described by Griffiths and Eftekhari (2008) was used for verification of their own experimental results. It can be used as a basis for the construction of a model taking account of the specific conditions of an experiment. The model was constructed and verified against weekly measurement results. In spite of the small number of measurements, the authors identified the need to create a larger number of practical recommendations to ensure the good quality of indoor air in schools. They also pointed out the need to use $\mathrm{CO}_{2}$ sensors in selected rooms for constant monitoring of the internal environment.

The present model was verified by means of field experiments. The measurement results were also used to verify the model of Griffiths and Eftekhari (2008) and to compare the two models. In the paper (Teleszewski and GładyszewskaFiedoruk 2018), a model was developed to give the carbon dioxide concentration in conference rooms with stack ventilation as a function of time, number of persons present and room volume. This model was accurate for an air change rate 
of $0.5 \mathrm{~h}^{-1}$. In the present work, the chief aim is to investigate the content of carbon dioxide in rooms having stack ventilation systems of differing capacity, and to develop a simplified model of total emission of carbon dioxide as a function of time, number of persons present and room volume, being further dependent on the air change rate. The model may be used as a simple tool for predicting the concentration of contaminants produced by humans, particularly the carbon dioxide concentration. The proposed model may be useful in designing HVAC control elements. It will be used as a basis for the creation of an application for designers of natural and mechanical ventilation systems, serving to determine carbon dioxide concentration in a room depending on the air change rate.

Carbon dioxide levels were measured in a conference room in the building of the Faculty of Civil and Environmental Engineering at Białystok University of Technology from April 2017 until February 2018.

\section{Materials and methods}

The investigation was conducted in two parts. In the first part, experimental measurements of temperature, humidity and carbon dioxide concentration were taken in the conference room. In the second part, a model for carbon dioxide concentration in rooms was constructed.

\section{Measurements of carbon dioxide concentration in the conference room}

Carbon dioxide levels were measured in a conference room in the building of the Faculty of Civil and Environmental Engineering at Białystok University of Technology (Fig. 1). This building is located in the city of Białystok, Poland, which lies in a temperate climatic zone, in an area with very clean external air (Peel et al. 2007a, b), and there are no industrial plants generating air pollution in the city or its neighbourhood. The annual average carbon dioxide concentration in the external air is $370.34 \mathrm{ppm}$.

In the room under analysis, the occupation time (time spent listening to talks, without leaving the room) lasted from 60 to $120 \mathrm{~min}$. The common interval in which analysis was carried out is marked on the graphs. Carbon dioxide concentration was recorded during a session over a time of 90 min, with the windows closed, unsealed (Fig. 2a-b) and open (Fig. 2c). Analysis was carried out with and without airing of the room with open windows prior to sessions. The time of airing is given in the last column of Table 1, and it ranged from 60 to $720 \mathrm{~min}(12 \mathrm{~h}$, i.e. the whole of the previous night). The air change rate in the room was regulated by unsealing or opening of windows. In the analysed room, with the windows tightly closed, the air change rate in the room was close to zero. Measurements were taken for a whole year, on selected days (as given in Table 1) and at different external temperatures, which led to different air change rates. No measurements were taken in the summer period (on days when the outside temperature was above $22{ }^{\circ} \mathrm{C}$, since mechanical ventilation was then replaced with the opening of windows). Internal environmental parameters were measured in accordance with recommendations given in the literature (Recknagel et al. 2006). Measurements were taken with a Testo recorder and IAQ probe, with parameters as described in the publications (Teleszewski and Gładyszewska-Fiedoruk 2018; Krawczyk et al. 2018). Probes were positioned at five measurement points situated $1.1 \mathrm{~m}$ above floor level, and this was assumed to be the height of a person's head during sessions in the conference room. Next, mean values were computed. The mean external concentration of $\mathrm{CO}_{2}$ at the time of the measurements was
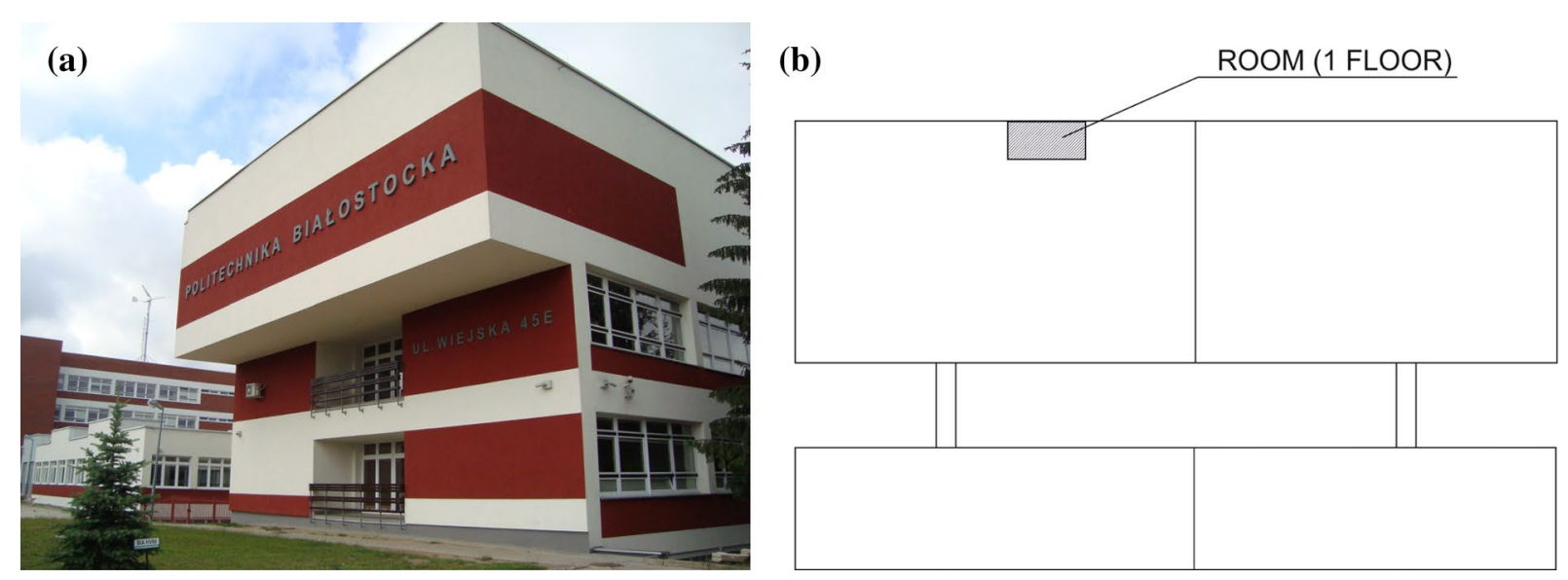

Fig. 1 Building of the Faculty of Civil and Environmental Engineering: a exterior view, $\mathbf{b}$ location of the analysed conference room on a plan of the building 
(a)

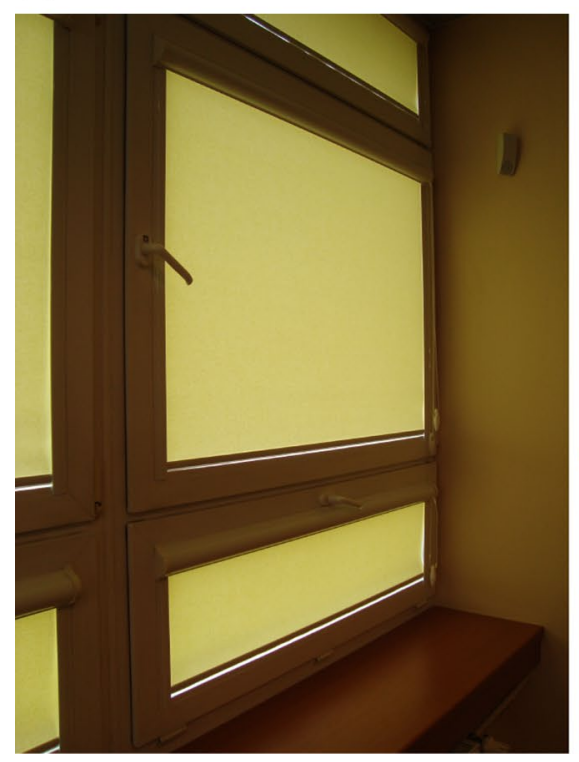

(b)

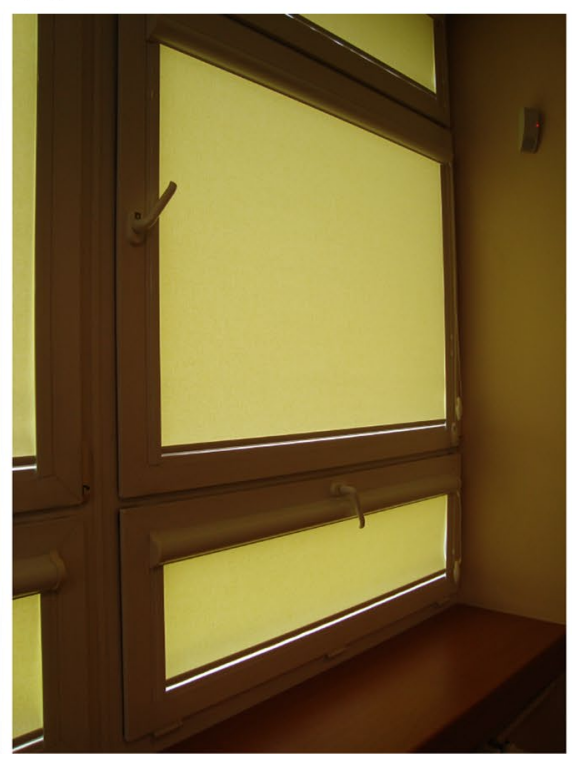

(c)

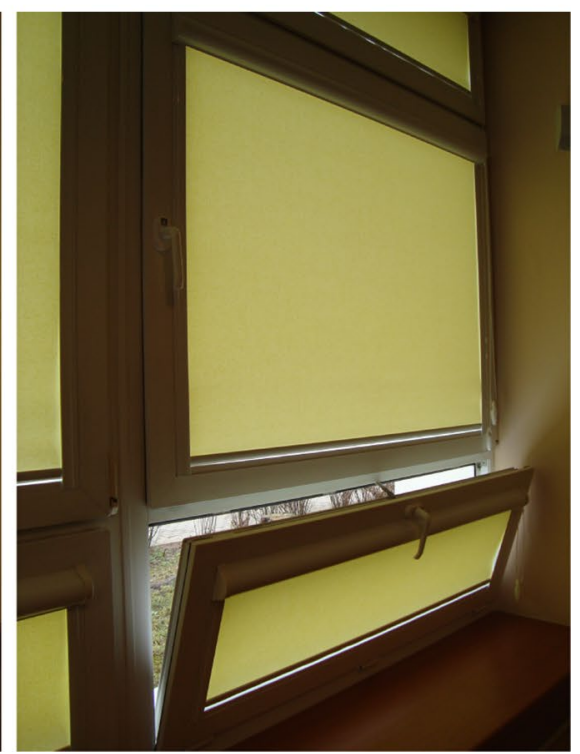

Fig. 2 Means used to regulate ventilation in the studied conference room: $\mathbf{a}, \mathbf{b}$ unsealing of windows, $\mathbf{c}$ opening of windows

Table 1 Details of the studied conference room at the time of measurements

\begin{tabular}{|c|c|c|c|c|c|c|c|}
\hline Series no. & Date & $\begin{array}{l}\text { Number of } \\
\text { persons } \\
n\end{array}$ & $\gamma=n / V$ & $\begin{array}{l}\text { Average relative } \\
\text { humidity }\end{array}$ & $\begin{array}{l}\text { Initial concentra- } \\
\text { tion of } \mathrm{CO}_{2}\end{array}$ & $\begin{array}{l}\text { Air change rate } \\
m\end{array}$ & $\begin{array}{l}\text { Time of prior airing } \\
\text { with open windows }\end{array}$ \\
\hline- & - & person & person $/ \mathrm{m}^{3}$ & $\%$ & ppm & $\mathrm{h}^{-1}$ & $\min$ \\
\hline 1 & $12 / 04 / 2017$ & 53 & 0.17 & 44.46 & 607 & 0.1 & 720 \\
\hline 2 & $17 / 05 / 2017$ & 48 & 0.16 & 48.82 & 457 & 0.001 & 720 \\
\hline 3 & 05/07/2017 & 54 & 0.17 & 55.71 & 754 & 6.7 & 60 \\
\hline 4 & $15 / 11 / 2017$ & 59 & 0.19 & 45.84 & 553 & 2 & 720 \\
\hline 5 & $13 / 12 / 2017$ & 53 & 0.17 & 41.73 & 536 & 1 & 720 \\
\hline 6 & $17 / 01 / 2018$ & 56 & 0.18 & 42.90 & 1658 & 8.2 & 0 \\
\hline 7 & $14 / 02 / 2018$ & 53 & 0.17 & 40.15 & $549 / 2304$ & $0 / 7.5^{\mathrm{a}}$ & 720 \\
\hline
\end{tabular}

${ }^{\mathrm{a}}$ Windows were opened after $22 \mathrm{~min}$ of the session, values relate to the periods $t<22 \mathrm{~min} / t>22 \mathrm{~min}$

$395 \mathrm{ppm}$. Results were recorded for each minute, each being the arithmetic mean of 30 measurements taken every $2 \mathrm{~s}$.

For the whole of the time, the mean air temperature in the room was maintained at $21.10^{\circ} \mathrm{C}$, and the relative humidity ranged from $40.15 \%$ in winter to $55.71 \%$ in summer. The relative humidity in the room was lowest in winter due to the use of convection heaters. The room has a uniform height of $3 \mathrm{~m}$ and a volume of $308.817 \mathrm{~m}^{3}$, and it seats a maximum of 65 persons. The only type of ventilation in use is natural ventilation (stack ventilation via ducts, and infiltration via slits around the door, which leads into a large corridor). The HVAC system in the conference rooms is equipped with temperature regulators. The window frames are airtight $\left(U=0.8 \mathrm{~W} /\left(\mathrm{m}^{2} \mathrm{~K}\right)\right)$ and made of $\mathrm{PVC}$, and they were replaced in 2007. Table 1 gives the numbers and dates of the measurement series, the number of persons present, the mean humidity, the initial carbon dioxide concentration, the air change rate in the room, and the time for which the room was aired prior to the session.

\section{Modelling carbon dioxide levels in conference rooms}

A previous study (Teleszewski and Gładyszewska-Fiedoruk 2018) has shown that the rate of increase in carbon dioxide levels in a conference room with stack ventilation depends primarily on the number of persons in the room and on the room volume. In the present work, analysis was also made of the dependence of $\mathrm{CO}_{2}$ concentration on the air change rate. Based on the measurements, a model was constructed to give 
Table 2 Coefficients of Eq. (2) used to determine the factor $k$

\begin{tabular}{|c|c|c|c|c|}
\hline \multicolumn{5}{|c|}{ Coefficients of Eq. (2) } \\
\hline$a$ & $b$ & $c$ & $d$ & $e$ \\
\hline 1.35 & -1.261 & 0.945 & -0.236 & 0.005 \\
\hline
\end{tabular}

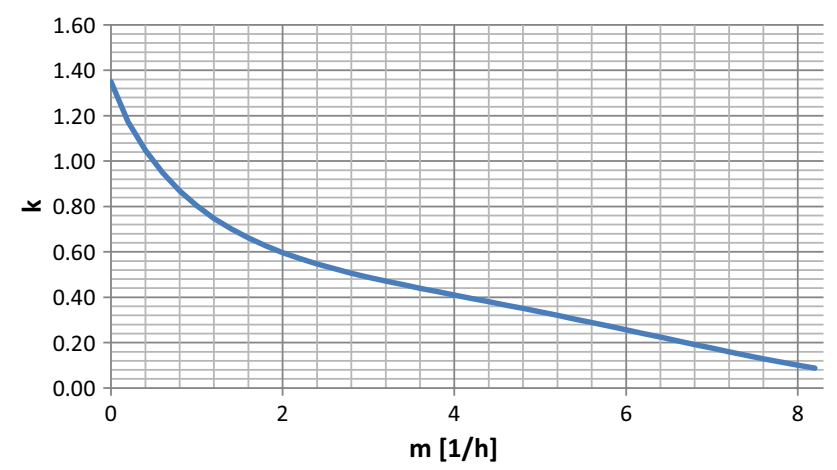

Fig. 3 The factor $k$ as a function of the air change rate $m$

the carbon dioxide concentration as a function of time, room volume, number of persons and air change rate:

$a_{\mathrm{CO}_{2}}=B \gamma t k+a_{\mathrm{CO}_{2}, t=0}, \quad \gamma=\frac{n}{V}$

where $B=180$ (Teleszewski and Gładyszewska-Fiedoruk $2018)$ is a constant value $\left(\mathrm{m}^{3} \mathrm{ppm} /(\right.$ person $\left.\mathrm{min})\right), t$ is time (min), $n$ is the number of persons in the conference room, $V$ is the room volume $\left(\mathrm{m}^{3}\right), a_{\mathrm{CO}_{2}, t=0}$ is the initial $\mathrm{CO}_{2}$ concentration (ppm), and $k$ is a dimensionless factor depending on the air change rate $m\left(\mathrm{~h}^{-1}\right)$ in the room:

$k=f(m)=a+b m+c m^{1.5}+d m^{2}+e m^{3}$

where the coefficients $a, b, c, d$ and $e$ are given in Table 2 . The coefficients $a-d$ of the formula (2) were obtained by interpolating the experiment data with a polynomial, in accordance with the procedure presented in Press et al. (1992).

Figure 3 shows the relationship between the factor $k$ and the air change rate $m$. The coefficient of determination $R^{2}$ for the relationship $k=f(m)$ is close to unity $\left(R^{2}=0.999\right)$.

It is noted here that the formula (1) is based on a formula derived in (Teleszewski and Gładyszewska-Fiedoruk 2018), where carbon dioxide concentrations in conference rooms were measured at a constant air change rate of $m=0.5 \mathrm{~h}^{-1}$.

The error of the $\mathrm{CO}_{2}$ model is calculated using the following formula:

$\delta a_{\mathrm{CO}_{2}}=\left|\frac{a_{\mathrm{CO}_{2}, \exp }-a_{\mathrm{CO}_{2}}}{a_{\mathrm{CO}_{2}, \exp }}\right| 100 \%$ where $a_{\mathrm{CO}_{2} \text {,exp }}$ is the measured concentration of carbon dioxide in the room and $a_{\mathrm{CO}_{2}}$ is the concentration computed from the formula (1).

\section{Results and discussion}

The graphical results of measurements of carbon dioxide concentrations in the conference room are shown in Fig. 4. A linear increase in carbon dioxide was observed in all measurement series, which may indicate that the capacity of the stack ventilation is too small (in all series the carbon dioxide concentration did not reach a stabilisation point). The concentrations of $\mathrm{CO}_{2}$ ranged from 457 to $3800 \mathrm{ppm}$. Similar conditions, although in different rooms, were reported by Dorizas et al. (2015a). In the study (Teleszewski and Gładyszewska-Fiedoruk 2018), measurements were taken in different rooms with different numbers of persons present, but at a constant air change rate of $0.5 \mathrm{~h}^{-1}$. The gradient of the graph of carbon dioxide concentration in the rooms as a linear function of time depended primarily on the number of persons and the room volume.

The smaller the volume and the larger the number of persons in the room, the larger is the gradient (Teleszewski and Gładyszewska-Fiedoruk 2018). In the present work, measurements were taken for different values of the air change rate in the conference room, in the range $0.001 \mathrm{~h}^{-1}<m<8.2 \mathrm{~h}^{-1}$. Studies were carried out under similar conditions by Dorizas et al. (2015a) and Yao and Zhao (2017).

Figure 4 shows a clear indication of the large impact of the air change rate on the gradient of the graph of carbon dioxide concentration as a linear function of time. The larger the air change rate in the room, the smaller the gradient. Figure 4 also shows a comparison of the model with experimental values obtained from six measurement series. The maximum mean relative error from individual series did not exceed $14.5 \%$, and the mean error for all measurements was $7.2 \%$. The formula (1) is functional both for rooms that have been aired prior to the session and for unaired rooms. It should be noted that the constructed model (1) may be applied only in the case of small conference rooms, with volumes up to $420 \mathrm{~m}^{3}$.

The above model is still applicable when the air change rate varies during a session, for example due to the opening of windows. Such a case (measurement series 7) is shown on the fifth graph, where windows were opened after $22 \mathrm{~min}$, causing the air change rate to increase from 0.001 to $7.5 \mathrm{~h}^{-1}$. To adapt the model to changing air flow conditions in the room, it is necessary to supply the variable air change rate at the current time $t$. Figure 5 also shows the graph of temperature as a function of time. Measurement series 7 took place during winter. 
Fig. 4 Comparison of measured carbon dioxide concentrations in the room with values computed from Eq. (1)
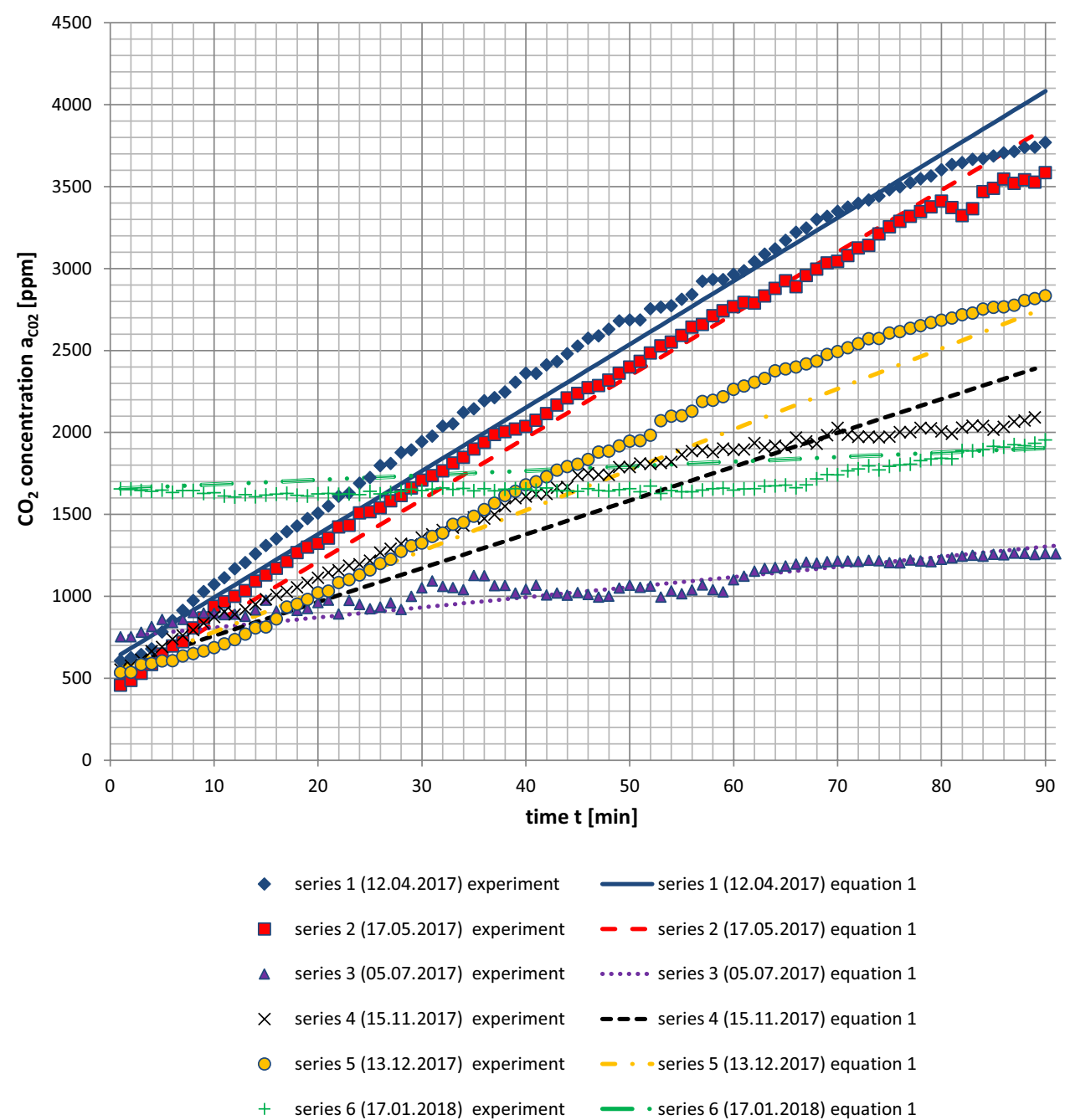

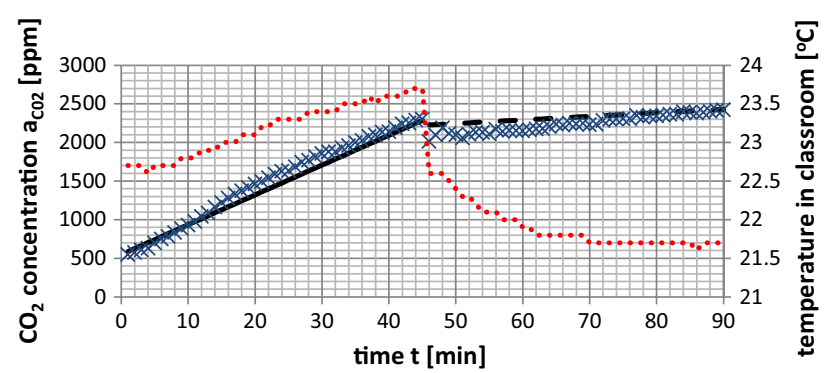

$\times$ experiment eq. $1(\mathrm{~b}=1.25, \mathrm{~m}=0)$

- eq. $1(b=0.15, m=7.5) \quad \ldots . . T=f(t)$

Fig. 5 Comparison of values from formula (1) with experimental data for $\mathrm{CO}_{2}$ concentration as a function of time from measurement series 7 , and changes in the room temperature during the experiment

The opening of the windows after 22 min of the session caused a sudden drop in temperature as cold outside air flowed into the room. A fall in temperature in the room also leads to an increase in the heat requirement of the system operating inside the room. Reducing the increase in carbon dioxide levels in a conference room by opening the windows undoubtedly leads to an increase in heating costs and is not a cost-effective method of improving the quality of air in the room.

Next the derived formula was compared with the experimental results and with the most commonly applied model for $\mathrm{CO}_{2}$ concentration in conference rooms (Almeida and Peixoto de Freitas 2014; Griffiths and Eftekhari 2008):

$a_{\mathrm{CO}_{2}, m}=a_{\mathrm{CO}_{2}, \mathrm{ex}}+\frac{G}{Q}+\left(a_{\mathrm{CO}_{2}, t=0}-a_{\mathrm{CO}_{2}, \mathrm{ex}}-\frac{G}{Q}\right) e^{-\frac{Q}{V} t}$,

$G=g n, \quad Q=V k / 3600$

where $G$ is the quantity of carbon dioxide generated by all persons in the room $\left(\mathrm{cm}^{3} / \mathrm{s}\right), g$ is the quantity of carbon dioxide exhaled by a person depending on the action being performed $\left(\mathrm{cm}^{3} / \mathrm{h}\right), a_{\mathrm{CO}_{2} \text {,ex }}$ is the external concentration of carbon dioxide (ppm), and $Q$ is the rate of flow of air through the room $\left(\mathrm{m}^{3} / \mathrm{s}\right)$. 
Simulations were performed for measurement series 2 and 6 , which were subject to significantly different air change rates $\left(0.0001 \mathrm{~h}^{-1}\right.$ and $8.2 \mathrm{~h}^{-1}$, respectively). The experimental value of the air change rate is in accordance with (Dorizas et al. 2015a, b). In the model (4), based on the literature (Recknagel et al. 2006), two values were adopted for the carbon dioxide generated by a person performing specified activities: $14 \mathrm{dm}^{3} / \mathrm{h}$ for a person at rest in a sitting position and $19 \mathrm{dm}^{3} / \mathrm{h}$ for a person performing light office work. In the case of measurement series 2 (Fig. 6a), using the value $14 \mathrm{dm}^{3} / \mathrm{h}$ for carbon dioxide exhaled per person, the mean error computed for the model (4) was $7.2 \%$ (Fig. 6a), while for the value $g=19 \mathrm{dm}^{3} / \mathrm{h}$ the mean relative error was $22.5 \%$ (Fig. 6a). The accuracy of the model (4) depends to a large degree on the value used for the quantity of exhaled carbon dioxide. In the case of measurement series 6 (Fig. 6b), for $g=14 \mathrm{dm}^{3} / \mathrm{h}$ and $g=19 \mathrm{dm}^{3} / \mathrm{h}$ the mean relative errors were $55.5 \%$ (Fig. 6b) and $49.5 \%$ (Fig. 6b), respectively. For large air change rates in the conference room, the cited model (4) has a fairly high relative error. The mean relative errors for measurement series 2 and 6 for the derived model (1) were, respectively, $4.7 \%$ and $1.6 \%$, indicating the high accuracy of the model at both large and small air change rates.

Heinzerling et al. (2013) claim that indoor environmental quality (IEQ) models may be a market driver and a motivating factor for designers, operators and owners of buildings. IEQ measurements may assist in the detection and correction of problems, but when such measurements are taken in a standard way, IEQ models can be applied to transform the measurements into results that can be used in evaluations and standards. Such standardised procedures enable the more appropriate use of IEQ models (Heinzerling et al. 2013).

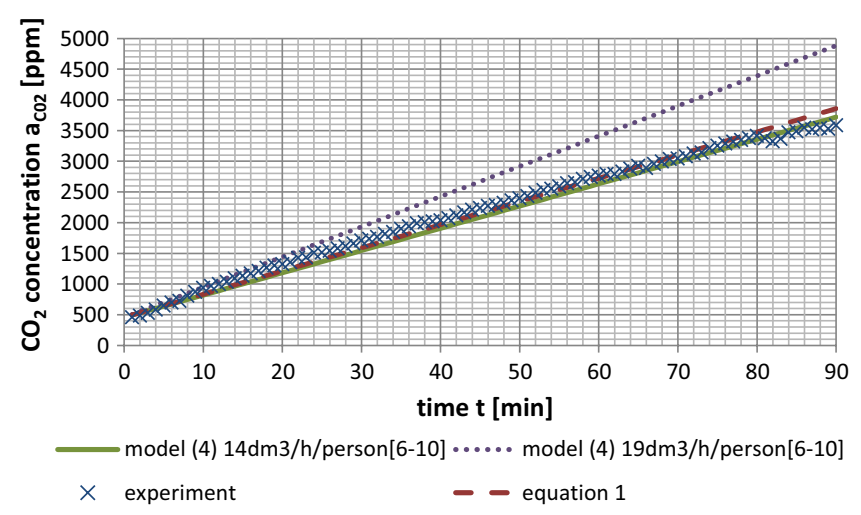

(a)

\section{Use of the simplified model of carbon dioxide concentration in systems for automatic regulation of ventilation in conference rooms}

This study has concerned only stack ventilation with different air change rates. Mechanical ventilation is undoubtedly more efficient than stack ventilation in maintaining adequate air quality, particularly when account is taken of the recovery of heat from the air removed from the room. The model (4) has been applied in the modelling of both stack ventilation (Almeida and Peixoto de Freitas 2014; Arendt et al. 2017; Griffiths and Eftekhari 2008; Kong et al. 2015) and mechanical ventilation (Liang et al. 2017). The simplified model of carbon dioxide concentration in conference rooms, as derived in the present work, may be used as an additional algorithm for controlling the operation of mechanical ventilation depending on the carbon dioxide concentration.

Figure 7 shows a concept for a ventilation system with heat recovery. Standard automated control of mechanical ventilation systems with heat recovery is based on the internal temperature, which is read from a temperature sensor in the wall of the room. The air flow rate in the room may be regulated based on readings from a carbon dioxide sensor. Based on the measured increase in carbon dioxide concentration $\Delta a_{\mathrm{CO}_{2}}$ in time $\Delta t$, the known room volume $V$ and the measured current air change rate $m$ in the room, it is possible to determine the number of persons present in the room using the formula (1):

$n=\frac{\Delta a_{\mathrm{CO}_{2}} V}{\Delta t B k}, \quad k=f(m)$

If the gradient of the increase in carbon dioxide concentration is too great, or the concentration exceeds the standard permissible value, then-based on the number of persons

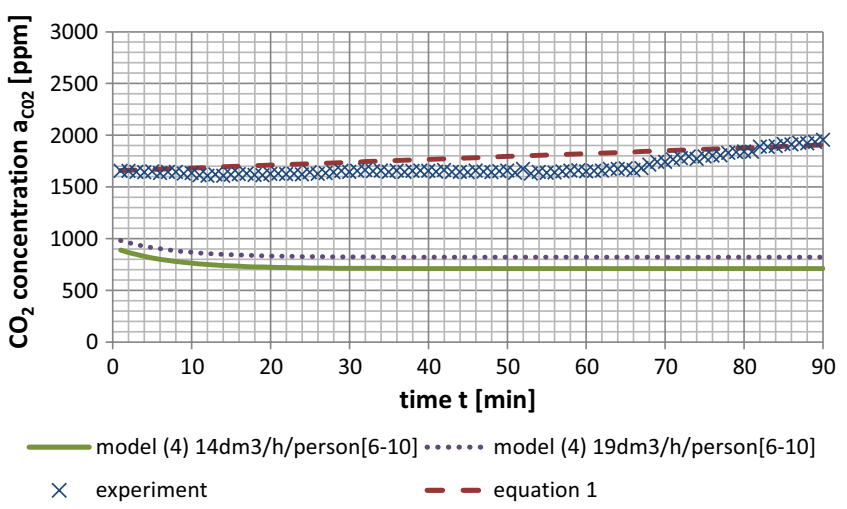

(b)

Fig. 6 Graphical comparison of model (1) and model (4) with experimental data for $\mathrm{CO}_{2}$ as a function of time, from a measurement series 2 (17 May 2017) and b measurement series 6 (17 January 2018) 
Fig. 7 Conceptual diagram for a system of automatic regulation of ventilation with heat recovery, with an additional sensor of carbon dioxide concentration in the conference room

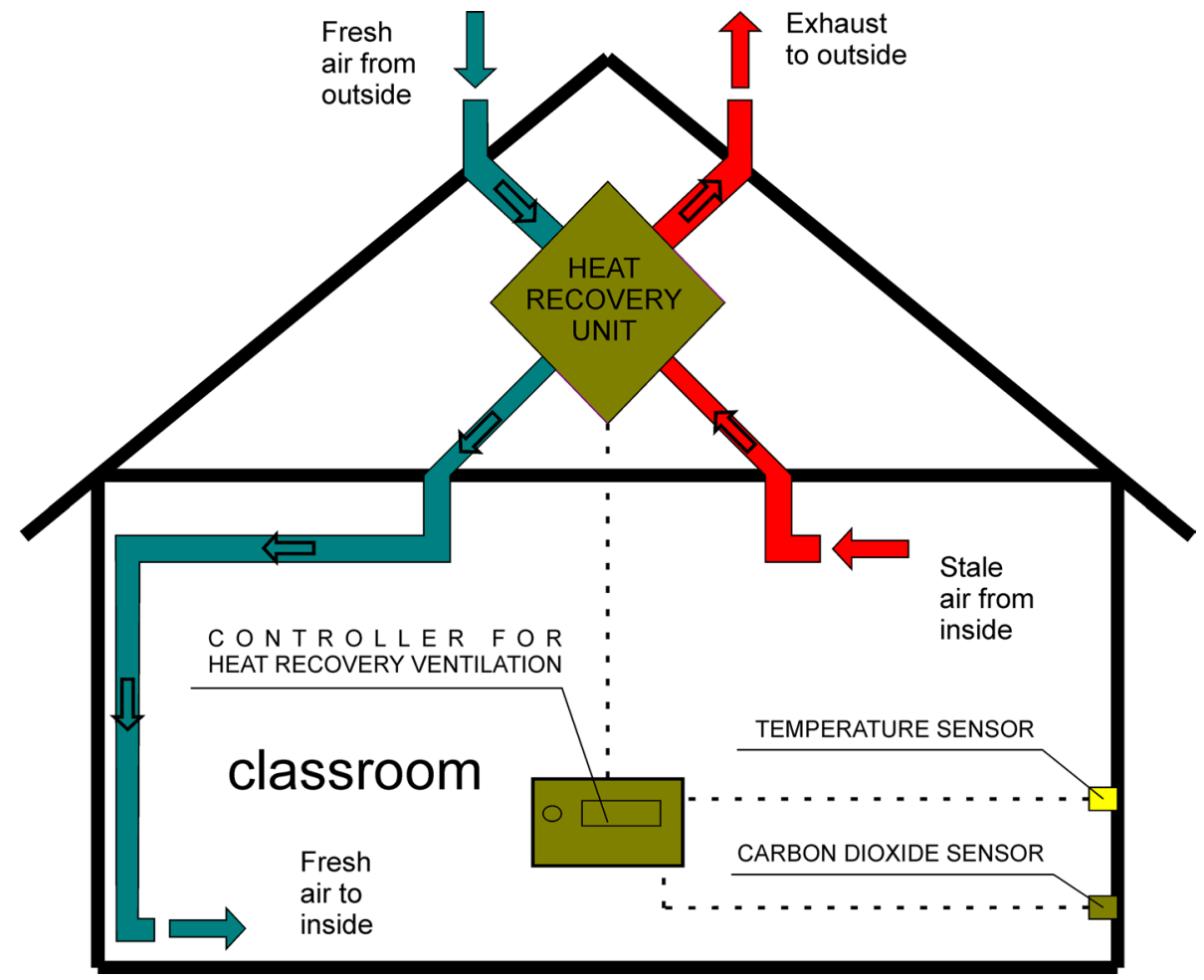

in the room as computed from (5) - the regulator will calculate a new air flow rate $Q_{2}$ for which the increase in carbon dioxide concentration is close to zero $\left(\Delta a_{\mathrm{CO}_{2}} / \Delta t \rightarrow 0\right)$. The change of flow rate from $Q_{1}$ to $Q_{2}$ may be effected by increasing the rotational speed of the impeller (from $r p m_{1}$ to $r p m_{2}$ ) and creating a new fan flow characteristic (Fig. 8a-b) or by opening the air damper in the ventilation ducts (Fig. 9a-b).

Regulation of the fan air flow by changing the rotational speed of the impeller and regulation of the capacity by adjusting the air damper are described in the literature (Design Guide for Heating 2006). A drawback of throttling the air damper is the additional hydraulic losses occurring at the damper. When regulation is performed by changing the rotational speed of the impeller, every change in rotational speed causes the formation of new flow, efficiency and power characteristics. Reducing the rotational speed of the impeller leads to a decrease in power on the fan shaft. From an energy efficiency point of view, it is more advantageous to regulate the flow by varying the rotational speed of the impeller (Design Guide for Heating 2006).

\section{Conclusion}

A comprehensive formula has been developed for predicting the concentration of carbon dioxide in rooms with stack ventilation where carbon dioxide is emitted by persons present in the room, taking account of the air change rate. Validation of the model was performed based on the results of measurements made in conference rooms during sessions. The model may be used both for rooms that have been aired prior to
Fig. 8 Conceptual diagrams for use of the described model (a) in conjunction with regulation of the fan capacity by varying the rotational speed of the impeller (b)
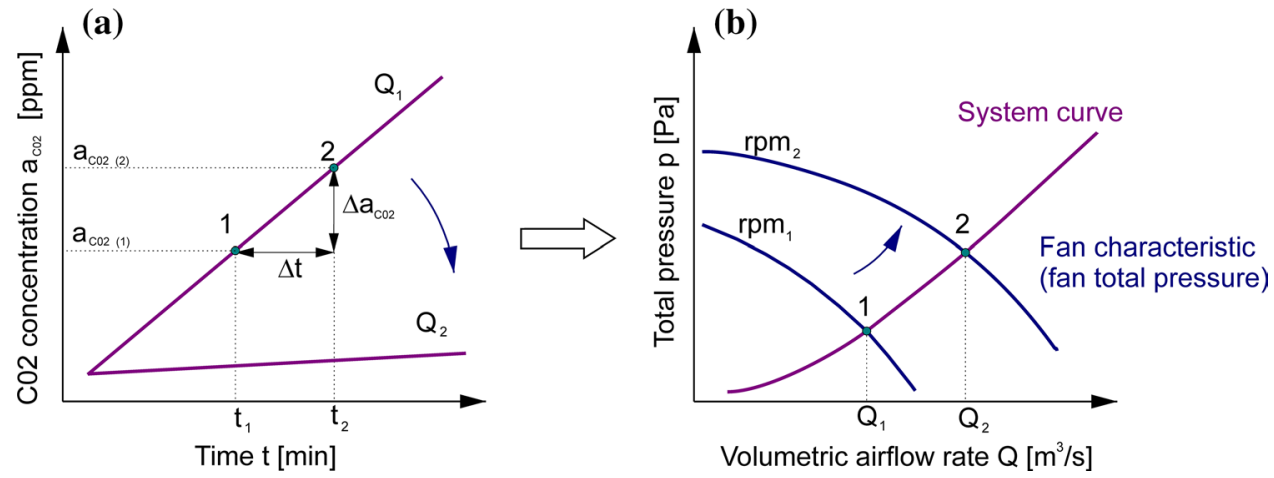
Fig. 9 Conceptual diagram for use of the described model (a) in conjunction with regulation of the fan capacity by throttling the air damper (b)

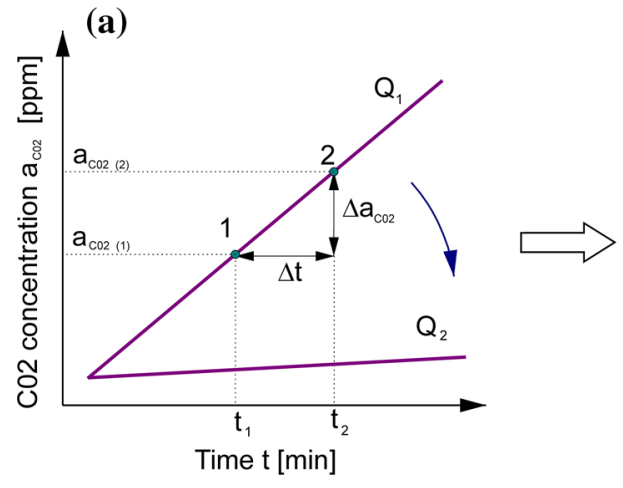

sessions and for unaired rooms. The model was verified by measurements made in one conference room, but the amount of ACH was different, and at different times of the year of measurements. The model presented here may be used in the future for performing IAQ analyses, and to support the design (optimisation with retention of energy efficiency) and response of ventilation systems to the value of carbon dioxide concentration measurements and the development of IAQ control methods.

The following conclusions may be drawn from the empirical measurements and simulations:

1. The concentration of carbon dioxide in a conference room increases throughout a session, most often in a linear manner.

2. Opening the windows significantly increases the effectiveness of gravitational ventilation and reduces the increase in carbon dioxide levels. It should be noted that the opening of windows during session breaks in the winter period significantly reduces the concentration of carbon dioxide in the room, but at the same time increases heat losses.

3. The model presented is useful both for air change rates close to zero (tightly closed windows) and for high air change rates.

4. The developed model may be used in the design of automatic regulation systems in ventilation installations and for the analysis of carbon dioxide concentrations in rooms.

This work also proposes an implementation of the presented algorithm in the regulation of mechanical ventilation based on carbon dioxide concentration. The model will serve as a basis for the creation of an application for designers of natural and mechanical ventilation systems, used to determine the concentration of carbon dioxide in a room depending on the air change rate. Further research will be carried out in rooms with mechanical ventilation, and the results will be compared with those obtained in the case of stack ventilation.
Acknowledgements The research was carried out at the Bialystok University of Technology and financed from a subsidy provided by the Ministry of Science and Higher Education of Poland, from the resources of the WZ/WBiIŚ/4/2019 and WZ/WBiIS/9/2019 work and a project co-financed by the European Regional Development Fund under the Podlaskie Voivodship Regional Operational Programme for the years 2007-2013 (1.1).

Open Access This article is distributed under the terms of the Creative Commons Attribution 4.0 International License (http://creativeco mmons.org/licenses/by/4.0/), which permits unrestricted use, distribution, and reproduction in any medium, provided you give appropriate credit to the original author(s) and the source, provide a link to the Creative Commons license, and indicate if changes were made.

\section{References}

Almeida RMSF, Peixoto de Freitas V (2014) Indoor environmantal quality of classrooms in Southern European climate. Build Environ 81:127-140

Arendt K, Krzaczek M, Tejchman J (2017) Influence of input data on airflow network accuracy in residential buildings with natural wind- and stack-driven ventilation. Build Simul 10(2):229-238

ASHRAE (2006) American society of heating, refrigerating and airconditioning engineers guidelines for design and constructions of health care facilities

Baranowski A, Ferdyn-Grygierek J (2015) Effect of calculation zoning on numerical modelling of ventilation airflows. Build Simul 8(1):73-79

Deng H-Y, Feng Z, Cao S-J (2018) Influence of air change rates on indoor $\mathrm{CO}_{2}$ stratification in terms of Richardson number and vorticity. Build Environ 129:74-84

Design Guide for Heating, Ventilating, and Air Conditioning Systems, U.S. Department of the Interior Bureau of Reclamation Reclamation Technical Service Center Mechanical Equipment Group (2006)

Dorizas PV, Assimakopoulos M-N, Helmis C, Santamouris M (2015a) An integrated evaluation study of the ventilation rate, the exposure and the indoor air quality in naturally ventilated classrooms in the Mediterranean region during spring. Sci Total Environ 502:557-570

Dorizas PV, Assimakopoulos M-N, Santamouris M (2015b) A holistic approach for the assessment of the indoor environmental quality, student productivity, and energy consumption in primary schools. Environ Monit Assess 187:259 
EN 13779 (2008) Ventilation of residential buildings. Requirements for the properties of ventilation and air conditioning

Griffiths M, Eftekhari M (2008) Control of $\mathrm{CO}_{2}$ in naturally ventilated classroom. Energy Build 40:556-560

Heinzerling D, Schiavon S, Webster T, Arens E (2013) Indoor environmental quality assessment models: a literature review and a proposed weighting and classification scheme. Build Environ 70:210-222

Khazaei B, Shiehbeigi A, Haji Molla Ali Kani AR (2019) Modeling indoor air carbon dioxide concentration using artificial neural network. Int J Environ Sci Technol 16:729-736

Kong M, Zhang J, Wang J (2015) Air and air contaminant flows in office cubicles with and without personal ventilation: a CFD modeling and simulation study. Build Simul 8(4):381-392

Krawczyk DA, Zielinko P, Rodero A (2018) Measurements of carbon dioxide concentration and temperature in dormitory rooms in Poland and Spain-a case study. During printing. IOP Conference Series: Earth and Environmental Science (EES)

Kusiak A, Li M, Zheng H (2010) Virtual models of indoor-air-quality sensors. Appl Energy 87:2087-2094

Liang W, Yang X, Chen F, Lv M, Yang S (2017) A pre-assessment and control tool for indoor air quality (PACT-IAQ) simulation in actual buildings. Procedia Eng 205:219-225

Mijakowski M, Sowa J (2017) An attempt to improve indoor environment by installing humidity-sensitive air inlets in a naturally ventilated kindergarten building. Build Environ 111:180-191

Peel MC, Finlayson BL, McMahon TA (2007a) Updated world map of the Köppen-Geiger climate classification. Hydrol Earth Syst Sci 11(5):1633-1644. https://doi.org/10.5194/hess-11-1633-2007

Peel MC, Finlayson BL, McMahon TA (2007b) Updated world map of the Köppen-Geiger climate classification. Hydrol Earth Syst Sci 11(5):1633-1644. https://doi.org/10.5194/hess-11-1633-2007

Press WH, Teukolsky SA, Vetterling WT, Flannery BP (1992) Numerical recipes in Fortran 77: the art of scientific computing, 2nd edn. Cambridge University Press, New York, pp 99-122

Recknagel H, Sprenger E, Schramek E-R (2006) Taschenbuch für Heizung + Klimatechnik 07/08: Taschenbuch für Heizung + Klimatechnik 2007/2008. einschließlich Warmwasser- und Kältetechnik Gebundene Ausgabe - 27

Rogula-Kozłowska W, Kozielska B, Majewski G, Rogula-Kopiec P, Mucha W, Kociszewska K (2018) Submicron particle-bound polycyclic aromatic hydrocarbons in the Polish teaching rooms: concentrations, origin and health hazard. J Environ Sci 64:235-244

Salis LCR, Abadie M, Wargocki P, Rode C (2017) Towards the definition of indicators for assessment of indoor air quality and energy performance in low-energy residential buildings. Energy Build 152:492-502

Silva S, Monteiro A, Russo A, Valente J, Alves C, Nunes T, Pio C, Miranda AI (2017) Modelling indoor air quality: validation and sensitivity. Air Qual Atmos Health 10(5):643-652

Szczurek A, Maciejewska M, Teuerle M, Wyłomańska A (2015) Method to characterize collective impact of factors on indoor air. Phys A 420:190-199

Teleszewski T, Gładyszewska-Fiedoruk K (2018) Changes of carbon dioxide concentration in classrooms-simplified model and experimental verification. Pol J Environ Stud 27(5):2397-2403

Tham KW (2016) Indoor air quality and its effects on humansa review of challenges and developments in the last 30 years. Energy Build 130:637-650

Wang Y, Cao Y, Liu B, Liu J, Yang Y, Yu Q (2016) An evaluation index for the control effect of the local ventilation systems on indoor air quality in industrial buildings. Build Simul 9(6):669-676

Weryszko-Chmielewska E, Kasprzyk I, Nowak M, Sulborska A, Kaczmarek J, Szymanska A, Haratym W, Gilski M, Jedryczka M (2018) Health hazards related to conidia of Cladosporiumbiological air pollutants in Poland, central Europe. J Environ Sci 65:271-281

WHO (1990) Indoor environment: health aspects of air quality, thermal environment, light and noise. World Health Organization, Geneva

Yao M, Zhao B (2017) Measurement of natural ventilation rate of residences in Beijing, China. Procedia Eng 205:3435-3440

Yu S, Zhang G, Ma Y, Yu Z, Feng G (2017) Numerical simulation study on concentration distribution of indoor pollutions by different natural ventilation strategies in Shenyang. Procedia Eng 205:1389-1396

Zender-Świercz E (2017) Analysis of the impact of the parameters of outside air on the condition of indoor air. Int J Environ Sci Technol 14:1583-1590

Zender-Świercz E (2018) Improving the indoor air quality using the individual air supply system. Int J Environ Sci Technol 15:689-696 